\title{
O “ARTE GÍMNÁSTICO” DE JERÔNIMO MERCURIAL E A HISTÓRIA DA EDUCAÇÃO DO CORPO: NOTAS SOBRE O ESQUECIMENTO
}

\author{
Jessica Vitorino da Silva Terra Nova ${ }^{1}$ \\ Fabio Zoboli ${ }^{2}$ \\ Hamilcar Silveira Dantas Junior ${ }^{3}$
}

\begin{abstract}
RESUMO
Partindo de uma das ideias apresentadas por Gagnebin (2006) sobre a necessidade de lutar contra o esquecimento, perpetuar a memória e manter viva a lembrança o presente ensaio pretende apresentar suscintamente o "Arte Gímnástico" levantando algumas questões que competem a importância de rememorar a imagem de Jerônimo Mercurial e da necessidade de se debruçar com mais afinco e profundidade a obra no sentido de que essa possa vir a enumerar diversas contribuições históricas sobre a educação do corpo no processo de civilização. Concluímos pela necessidade de leitura e análise da obra de Mercurial pela noção de Clássico e pela urgente crítica histórica da mesma sob o prisma da relação Documento/Monumento.

Palavras-chave: Educação do corpo; Ginástica; Jerônimo Mercurial; História; Memória.
\end{abstract}

\section{THE "ARTE GÍMNÁSTICO" OF JERÔNIMO MERCURIAL AND THE HISTORY OF EDUCATION OF THE BODY: NOTES ABOUT FORGETTING}

\begin{abstract}
Starting from the ideas presented by Gagnebin (2006) about the need of fight against the forgetting, perpetuate the memory and keep alive the memory, this essay qims to briefly present the "Arte Gímnástico" raising a few questions about the recall the memory of Jerônimo Mercurial and the need of going over deeply in his work, in na effort to to enumerate some historical contributions about the education of the body in the civilization process. We concluded we need to read and analyze Mercurial's work by the notion of Classic and by the urgent historical critico $f$ it through the prism of Document/Monument relation.
\end{abstract}

Keywords: Education of the body; Gymnastics; Jerônimo Mercurial; History; Memory.

\section{Introdução}

O "Arte Gímnástico", é um dos primeiros tratados de Medicina com feições voltadas à Fisioterapia e Ginástica e foi publicado em pleno auge do movimento renascentista no século XVI, mais precisamente em 1569. Uma obra monumental ${ }^{4}$ que propõe uma análise da ginástica (dos exercícios físicos) sob três pontos de vista: 1) ponto de vista histórico, pois apresenta, em certa medida, a origem/o surgimento de cada um dos exercícios bem como do campo de conhecimento, a medicina, que abarca essa disciplina e das instalações arquitetônicas destinadas a tal prática em recorrência a documentos históricos e/ou bibliográficos de autores "antigos"; 2) ponto de vista médico por 
contextualizar a ginástica como parte deste campo enquanto uma possibilidade de "curar" doenças e convalescências sob um ponto de vista terapêutico e; por fim, 3) ponto de vista higiênico por atrelar a ginástica também enquanto possibilidade de conservação da saúde.

Como é de se saber, a ginástica foi por muito tempo definida como "arte de exercitar o corpo nu" ou como "arte das exibições corporais humanas". Em todo o seu percurso histórico, a ginástica enquanto prática foi se ressignificando de acordo com o contexto e atribuindo para si diversas finalidades entre as quais, as que refletem na educação humana. A posteriori a ginástica adquiriu o status de Educação Física, atualmente considerado um campo de conhecimento que possui como focos de análises e de estudos temáticas que giram em torno do corpo e do movimento humano, logo o seu contingente de exercícios e atividades que se voltam para o cumprimento dos mais diversos objetivos.

A Educação Física também é um campo atrelado às ciências da saúde e neste sentido carrega em sua base de fundamentação aspectos voltados às possibilidades médicas no que diz respeito à conservação e à cura de enfermidades e convalescências. Aliás, a elucubração da Paidéia por Jaeger (1995) faz referência a influência médica no campo da Filosofia no contexto da antiguidade, principalmente no que se refere a questão da fundamentação e/ou da relevância da ginástica enquanto prática social no cerne da formação humana. A figuração da Medicina na história da Paideia, fortalece contribuições desta ciência para além das questões referentes à ela mesma. Neste sentido, não é de se estranhar os motivos para a ciência médica ter guiado e ter sido a base que legitimou a ginástica e, a posteriori, a Educação Física, durante séculos. Talvez, a doutrina referente à conservação da saúde do homem seja a mais verdadeira criação do espírito grego. Ora,

A ciência médica não só fomenta a compreensão dos problemas da Medicina em vastos círculos, mas, concentrando-se num terreno parcial da existência humana, o do corpo, alcança conhecimentos e decisiva importância para a composição filosófica duma nova imagem da natureza humana e, portanto, para uma mais perfeita formação humana. (JAEGER, 1995, p. 969-70)

Sob tais e outros aspectos, devemos elucubrar a relevância de um considerado "primeiro" tratado sobre os exercícios físicos no desmembramento de estudos, pesquisas, descobertas e avanços principalmente no quesito que confere a história da ginástica ou dos parâmetros voltados para a questão da educação do corpo.

Pouco mencionada nos estudos em História da Educação Física, em História da Educação do corpo e/ou em quaisquer outros estudos provenientes de campos próximos ou similares consideramos que a obra de Mercurial foi taxativamente "esquecida". Conforme Michael Pollak (1989), o esquecimento e a gestação do silêncio de algumas vozes na história têm vários motivos: tensões políticas, sociais, econômicas e culturais. Os ditos e os não-ditos flutuam conforme a combinação de forças em disputa, cabendo aos que fazem História recuperar as memórias esquecidas, revelando suas vozes e ensinamentos sobre o passado e também para o presente.

Entendemos que o esquecimento, nos estudos de História da Educação Física, da obra de Mercurial, tão rica e excepcional em termos de contribuição, ao menos em suas proposições, tem muito mais vínculos a uma compreensão da modernidade e os escritos dos iluministas como "criadores" de uma Educação Física sistematizada, do que propriamente um esquecimento de sua contribuição, ou seja, é uma tomada de posição teórico-política. Em contrapartida a essa posição, entendemos que o "Arte Gimnástico" reúne conhecimentos de diversas áreas e estabelece um parâmetro de práticas ginásticas 
que eram realmente úteis para o contexto em que se apresentara. As fontes revelam que Mercurial, ao escrever sua obra, fez uso do seu profundo conhecimento acerca do mundo clássico e utilizou em suas proposições ideias pautadas em pensadores como Galeno, Aristóteles, Platão, Séneca, Avicena, Hipócrates, Vitruvius e outros como Plínio "El Viejo", Plutarco, Homero, Pausanias e outros.

Assim, propomos com este ensaio questionar, primeiramente, sobre o papel do historiador como aquele que se propõe a escrever uma história, rememorar uma figura, um personagem histórico, aquele que almeja ressuscitar a alma, dar vida aos mortos, eternizar uma memória sob as veredas de um "mar desconhecido", o "mar sem caminhos". Em outra instância, questionar sobre quais relevâncias são possíveis encerrar em tal disposição, principalmente em relação as conjecturas pautadas não apenas acerca da obra, mas também da figura de Jerônimo Mercurial.

"É necessário lutar contra o esquecimento", um comando de ordem ao historiador! Sem esquecer os desafios e as seduções inerentes ao caminho desconhecido que se pretende percorrer, em outras palavras, objetivamos apresentar suscintamente o "Arte Gímnástico", levantar algumas questões que competem a importância de rememorar ${ }^{5}$ a imagem de J. Mercurial ${ }^{6}$ e da necessidade de se debruçar com mais afinco e profundidade a esta obra no sentido de que essa possa enumerar diversas contribuições históricas sobre a educação do corpo no processo de civilização.

\title{
Memória e silêncio
}

\begin{abstract}
Ao chegar numa costa desconhecida, Ulisses muitas vezes se pergunta quem são os habitantes dessa região, se são "mortais", "comedores de pão", ou se são outros - monstros, deuses, animais. Na história de Ulisses, bem como em vários contos para crianças, trata-se de sair do território do inumano e do mítico para, pouco a pouco, depois de várias provações, chegar ao mundo reconquistado da condição humana. A perdição de Ulisses nesse mundo mítico, simultaneamente aterrorizante e sedutor, é assinalada pela tempestade de nove dias e nove noites que o afasta das terras conhecidas dos Cícones para mergulhá-lo no mar desconhecido das ilhas fabulosas onde vai errar até chegar na corte dos Feácios: ilhas dos Lotófagos, dos Ciclopes, de Éolo, de Circe, das vacas de Apolo, de Calipso, sem falar em Caríbdis e Scila nem das Sereias! Nessas errâncias, Ulisses não encontra mais nenhum mortal, digamos, normal. Essa passagem é assinalada, de maneira belíssima, no primeiro episódio, o dos Lotófagos - esse povo pacífico, vegetariano e perigoso: perigoso porque representa através do loto, "doce como mel", a grande tentação contra a luta a Odisséia inteira: o esquecimento. [...] Os Lotófagos não ameaçam nem matam, mas, de maneira muito mais perniciosa, oferecem o eterno presente do esquecimento. Este episódio indica, desde o início, que a luta de Ulisses para voltar a Ítaca é, antes de tudo, uma luta para manter a memória e, portanto, para manter a palavra, as histórias, os cantos que ajudam os homens a se lembrarem do passado e, também, a não se esquecerem do futuro (GAGNEBIN, 2006, p. 14$15)$.
\end{abstract}

Lutar contra o esquecimento para manter a lembrança, lutar contra a morte pela palavra viva e rememorativa foram intenções cravadas por poetas históricos que na busca pelas causas verdadeiras as registravam na tentativa de apreendê-las no combate da 
essência efêmera da transmissão oral. Trata-se, sobretudo, de uma luta pela palavra, pela escrita, pela permanência e perpetuação de uma memória real e viva. Gagnebin (2006, p. 11) afirma que a escrita "[...] deseja perpetuar o vivo, mantendo sua lembrança para as gerações futuras, mas só pode salvá-lo quando o codifica e o fixa, transformando sua plasticidade em rigidez, afirmando e confirmando sua ausência - quando pronuncia sua morte".

Entre essa necessidade atual de se escrever História, de transmitir "verdades" através da palavra temos que considerar os desafios que deve percorrer aquele que deseja se aventurar nos territórios sem inscrições prévias, incógnitos e indefinidos. Em meio a Lotófagos, Ciclopes, Éolo, Circe, vacas de Apolo, Sereias etc. - personificações que perpassam a narrativa dos episódios errantes vividos por Ulisses na Odisséia - é possível sintetizar alegoricamente os interstícios vividos por um historiador quando o mesmo se dispõe, assim como o personagem, a mergulhar no mar do desconhecido, aterrorizante e sedutor, e a enfrentar as tempestades que o faz se afastar das terras conhecidas.

A alegoria Homérica retomada na leitura de Gagnebin (2006) com a finalidade de conferir uma definição de cultura, é analisada, sobretudo, a partir da interpretação de Adorno e Horkheimer (1985) que se pauta na "formação do sujeito pela dominação da natureza e pela auto-repressão". Para a autora, Adorno e Horkheimer encontraram na obra

[...] a descrição da construção exemplar do sujeito racional que, para se construir a si mesmo como "eu" soberano, deve escapar das tentações e das seduções do mito, assegurando seu domínio sobre a natureza externa e, também, sobre a natureza interna, sobre si mesmo (GAGNEBIN, 2006, p. 13).

A ilustração da autora em diálogo com as diferenciadas interpretações - como a passagem da infância para a idade adulta, ou mesmo a descrição de um itinerário geográfico - pautadas por outros pesquisadores que se debruçaram sobre a Odisséia faznos perceber o quanto essa alegoria têm a nos dizer e alertar, ao mesmo tempo nos deixar atentos à necessidade em assumir uma postura crítica e reflexiva frente aos caminhos e descaminhos que se percorre no ato histórico.

Ora, a reflexão pautada acima sob uma breve leitura da obra de Gangnebin (2006) "Lembrar, escrever, esquecer" - não foi conferida à toa, principalmente quando releva o sentimento pela qual predispõe ao querer enveredar os caminhos, os rumos que nos levam ao mar desconhecido que, neste caso, nada mais é que a obra de Jerônimo Mercurial. A relevância desta reflexão é explicitada frente aos caminhos e descaminhos trilhados por um historiador, principalmente no tocante ao reconhecimento racional para o fazer histórico. Tais colocações, apontadas resumidamente, também propõe refletir acerca do estabelecimento de comportamentos éticos e coerentes necessários ao enfrentamento deste mar misterioso, assim como é todo o processo de descortinar e de constituição da história.

Em meio a um processo culminante do "grande movimento renascentista", marcado pela "redescoberta do mundo e do homem", pelas grandes revoluções em termos de conhecimento em diversas áreas, pela constituição de uma cultura humanista e revalorização do pensamento e da arte referente à antiguidade clássica e ainda, pelas inúmeras transformações e mudanças nos mais diversos setores - políticos, sociais, econômicos, culturais, etc. - nasce Jerônimo Mercurial (1530-1606) este que publica em 1569 o "Arte Gímnástico", sua obra mais famosa.

Mercurial, figura importante e destaque nos espaços científicos da sua época, atingiu sua maior popularidade quando da publicação da sua obra mais original, supracitada. Descendente de antigas e respeitadas famílias forolivenses concluiu um curso 
de Letras Humanas dedicando-se profundamente a filosofia (esta, a posteriori, ligada intimamente a medicina), as matemáticas e a língua grega e estudou medicina na Universidade de Bolonha doutorando-se em Pádua no ano de 1555. Desta feita, tornou-se um grande e famoso humanista, médico e filólogo da sua época.

As obras científicas publicadas pelo autor totalizam em torno de vinte e quatro livros, divididas em dois grupos: 1) escritos diretamente redigidos por ele; 2) escritos retirados das suas lições universitárias. Vale salientar que as mais diversas edições/versões de suas obras foram publicadas e difundidas em várias cidades da Itália (Veneza, Pádua, Bolonha e Forli) e do continente europeu (Paris, Bruxelas, Frankfurt, Lyon e Estrasburgo), fato pouco comum, mas que demonstra a força e a popularidade do livro, bem como o prestígio do autor.

Durante a estadia de Mercurial em Roma - onde coletou os dados e todo o material para a constituição da sua obra - travou contatos e amizades (graças a essas teve livre acesso às grandes bibliotecas, onde teve oportunidade de estudar os escritos de autores antigos, como também os antigos códigos e documentos) pelos quais aderiu referências e/ou influências concatenadas em seus estudos e pesquisas. Dentre estas estão figuras imponentes como: o cardeal Alejandro Farnesio a quem foi dedicado um de seus livros; o frei agostiniano Onofre Panvinio (Onuphrius Panvinius), amante da antiguidade clássica estudou a fundo as antiguidades desportivas; o humanista Justo Lipsio e; o jovem Galileu Galilei, com quem trava uma profunda amizade a qual os mantém sob uma profícua troca de correspondências.

Após muitos anos dedicados ao serviço da ciência e da humanidade, no percurso de sua carreira magistral, formaram-se seus muitos discípulos. Doutores da época consideraram-no glorioso e um dos mais eminentes filólogos. Afirma Di Donato (apud MERCURIAL, 1973, p. XVI) que "tenía una gran elocuencia y sabia explicar sus lecciones con gran amenidad y aprovechar todas las bellezas de la lengua latina" e que era "persona bella y robusta, de modales gentiles, discreto de costumbres, frugal en la comida, siempre de acuerdo con su familia, muy religioso y lleno de caridad cristiana".

Mercurial, ao final da sua carreira, retorna a Forli, sua cidade de origem, para passar os dois anos finais de sua vida entregue à suas lembranças e a sua família. Em Outubro de 1606, ficou doente por conta de uma complicação causada por Cálculos Renais. Científico até o final de sua vida pediu ao seu médico para fazer uma necroscopia, a autopsia confirmou seu próprio diagnóstico. Nas primeiras horas do dia 9 de Novembro desse mesmo ano veio a falecer; e por desejo seu, foi enterrado na Igreja de S. Mercuriale, junto à tumba de seu primeiro filho, Giovanni, falecido em Salamanca. Em seu túmulo não foi registrado qualquer epitáfio. Apenas trezentos anos após a sua morte, em 1960, foi feito tal registro por iniciativa de alguns fiéis em reverência à sua memória.

Na obra "Arte Gimnástico" alguns questionamentos foram postos por Mercurial de modo a guiar-lhe na constituição de seu tratado ginástico e dessa forma se empenhou em fazer um apanhado histórico sobre a origem da Medicina e alguns de seus desdobramentos (Profylática ou Hijiene e Terapéutica); descrever sobre os exercícios físicos e seus efeitos medicinais de maneira individual e específica de cada um deles; manifestar as regras gerais ou comuns a todos os exercícios constituindo uma espécie de guia para que qualquer pessoa que tenha interesse possam colocá-lo em prática; apresentar as diferenças dos exercícios (preparatório, exercício simples ou apótereopético), os efeitos de cada um deles, e das diferenças desses exercícios; apresentar as classes das enfermidades dos corpos e da saúde, os exercícios para os corpos convalescentes e dos velhos, os exercícios para os corpos sãos; e descrever os lugares que se devem praticar os exercícios, o tempo apropriado para a prática, a quantidade e o modo de se exercitar. 
Daqui é possível perceber que muitas tensões e problemáticas foram, estão e ainda podem ser travadas dentro deste contexto tanto no que se refere perspectiva da vida pessoal e acadêmica quanto sob o aspecto que concerne à constituição da obra "Arte Gimnástico" por Mercurial. O esquecimento ou o não reconhecimento desta figura científica já é um cerne característico desde a sua morte. Como visto (e como ainda veremos) e dito anteriormente, há uma dificuldade imensa de realizar esse estudo na medida em que as fontes e as referências que falam sobre J. Mercurial são escassas. Para a construção deste ensaio foi feito um levantamento onde foram detectados alguns indícios: biografias curtas em sites estrangeiros, obras que apontam apenas acerca da sua existência sem oferecer nenhuma informação referente ao seu possível legado etc. Dentre as oito edições e das demais versões publicadas da obra ${ }^{7}$, a única fonte acessada e que tem servido de embasamento é datada de 1973 publicada em Madrid pela Delegación Nacional de Educación Física y Deportes. - o conteúdo e o texto apresentado são de reprodução similar a edição de 1845 - a primeira versão/tradução mundial do original latino para uma língua vernácula. É totalmente fiel ao original, em termos de estrutura interna.

Para Chartier (2009, p. 41) "[...] as obras conservam uma identidade perpetuada, imediatamente reconhecível por seus leitores ou ouvintes". Levando em consideração que uma obra é um complexo de sentidos configurada a partir das relações sociais, políticas, econômicas etc. as quais atribuem características específicas nos modos de ver de uma sociedade, torna-se necessário levar em conta as diferentes leituras e interpretações que uma única obra pode conferir, na medida em que esta se perpetua a partir dos signos que constituem um indivíduo ou um grupo social nos interstícios de um determinado tempo ou espaço. Sendo assim, uma obra de 1973, por exemplo, não poderá ser analisada da mesma forma que uma de 1569, pois os aspectos culturais são transitórios, mutáveis, efêmeros.

Interessante conjecturar que a edição de 1845 , citada anteriormente, tratou-se de um raríssimo exemplar, com efeito, sofreu várias adversidades desde a sua publicação, o livro não vendia. Os impressores, dado o fracasso de sua iniciativa, decidiram queimar as cópias restantes. Diz-se que as possíveis causas do fracasso do livro, é que em 1845 a Espanha vivia um momento de tensões políticas. Segundo o editor Pienavieja Del Pozo:

La vida española era um alertado reposo entre dos guerras carlistas; concluída la primera en 1839 con el Convenio de Vergara (pero continuada hasta 1840 por Cabrera) y reanudada la segunda em 1847, para terminar definitivamente em abril de $1849 \mathrm{com}$ el reconocimiento de Isabel II como reina por todos los españoles. No era, pues, tempo propicio para estas lecturas novedosas (MERCURIAL, 1973, p. XXXIV).

Diante dessa informação há de se obtemperar os riscos de desaparecimento que a obra enfrentou. Trata-se de um fato bastante instigante ao pesquisador. O teor de renovação pautado na obra já alertava e educava, de certo modo, a população na tomada de novos hábitos físicos e higiênicos, principalmente. Por que as obras não estavam sendo vendidas? Qual o interesse dos impressores em queimá-las? Qual era a situação política desse Estado pela qual influenciou todo esse processo de fracasso ao ponto de se querer "apagar um rastro", extraí-la do campo da memória coletiva ${ }^{8}$ impossibilitando-a transpor a um determinado tempo e espaço? Já dizia Chartier (2010, p. 24-25) que "[...] o escrito é o instrumento de poderes temíveis e temidos", ora, "interrogar-se sobre a autoridade atribuída (ou negada) ao escrito e sobre as lutas para o confisco (ou a divulgação) de seus poderes talvez não deixe de ser pertinente para a compreensão do presente".

Os exercícios de força, destreza e agilidade em uso entre os antigos gregos e romanos - e os efeitos que os mesmos produzem em benefício à saúde do indivíduo ora 
apresentados na obra pelo autor estão colocados sob a perspectiva de um dos quatro preceitos essenciais para a conservação da saúde ${ }^{9}$ atrelada a um modelo de civilização e educação de um corpo "humano" e "moderno". "El arte jimnástico es cierta facultad que considera la oportunidad de todos los ejercicios y enseña poniendo por obra la diversidad de éstos, ya para conservar la buena salud, y ya para adquirir y retener mejor disposición del cuerpo" (MERCURIAL, 1973, p.11).

O corpo carrega em si uma história seja esta, parte de uma construção individual ou coletiva em suas relações com o mundo. Ao longo desta história padrões vão sendo estabelecidos, sistematizados, incorporados, quiçá transformados a fim de que tal corpo se adeque a um determinado modelo notadamente pautado sob uma perspectiva política apresentada em conformidade aos interesses do sistema de poder. Neste contexto pode-se afirmar que o ser humano vive em processo de metamorfose corporal constante na medida em que seu corpo pode ser investido por relações de poder e de dominação que se advém por meio das mais diversas escalas. "É dócil um corpo que pode ser submetido, que pode ser utilizado, que pode ser transformado e aperfeiçoado" (FOUCAULT, 2000, p.118).

A fim de se apoderar, controlar, disciplinar, docilizar e aperfeiçoar é necessário pensar os cuidados destinados ao corpo, é necessário pensar sobre a melhor forma de agir sobre ele, de manter seu equilíbrio, de prolongar a vida. Para tanto, supõe-se a proposição de uma educação para o corpo, do corpo, que através de métodos agrega estratégias intermediadas por saberes e práticas diversas que vão "da higiene às boas maneiras, dos usos da água como lugar de prazeres específicos ou como local de trabalho aos banhos como limpeza, dos modos de alimentar-se, vestir-se, amar, dos modos de adoecer, de curar-se, de nascer e morrer" (OLIVEIRA, 2006, p. XIII).

Brandl Neto e Campos (2010, p. 89) afirmam que os métodos/pedagogias enquanto processos existentes desde há muito tempo nos conventos, nos exércitos etc., e que estão presentes também em escolas, hospitais, e outros locais - são os que permitem obter o controle sobre o corpo; os que realizam a constante sujeição de sua força e lhe impõe a relação de docilidade e utilidade; e ainda o que se pode denominar de disciplinas, que aumentam as forças do corpo em termos econômicos de utilidade ou diminuir essa mesma força em termos políticos.

A ginástica que agrega a prática dos exercícios físicos sistematizados, através de todo um contexto histórico, também foi pautada enquanto um dos métodos utilizados para disciplinar os corpos, imbuí-lo de bons hábitos e conservar a saúde frente à claras imagens da modernidade pautadas sobre a apologia da civilização e do progresso. A ginástica enquanto uma prática sociocultural agregou influências que caracterizaram os tons de cada tempo, de cada época. A esta também foram forjadas finalidades "úteis" representativas de ideais concernentes ao contexto em que se apresentaram.

O que seria a ginástica senão uma pedagogia higiênica, tática sempre atualizada e ressignificada de investimento no corpo, na intimidade de sua fisiologia, na gestão de seus desejos? Pergunta e aponta Soares (2008, p. 75). As pedagogias, afirma Vigarello (1978, p. 9), de acordo com a mesma autora, são portadoras de preceitos que esquadrinham e dão forma ao corpo a fim de submetê-lo a normas que sugerem imagens, esboçam gestos que induzem silenciosamente posições e comportamentos. Essas práticas, elaboradas para educar o corpo buscam incorporar, mais precisamente, através dos lentos processos de constituição e transformação da sensibilidade posta em cada época, uma racionalização da vigilância sobre o outro e sobre si mesmo, sobre o próprio corpo.

Há uma constante atualização das pedagogias, há um incremento racional sempre mais intenso e extenso nos modos de intervir no corpo, medindo a 
cada dia mais intensiva e progressivamente todas as suas funções e toda a sua expressão. Aliás, a idéia mesma da medida em tudo o que concerne ao corpo traz elementos importantes para uma leitura dos processos de sua domesticação e docilidade. É possível pensar que a medida compõe mais seguidamente os horizontes imediatos de onde se pode apreciar os objetivos e resultados das muitas intervenções sobre o corpo (SOARES, 2008, p. 76).

Olhar para um corpo construído historicamente é preciso estar atento a tais evidências, primeiro em relação às constantes atualizações, referentes ao campo pedagógico, que são pautadas a partir dos inúmeros contextos e intenções pela qual são atribuídas as ações interventivas. Ou seja, uma pedagogia deve se adequar conforme o contexto e os sentidos conferidos a esta e, neste aspecto, é que necessitam ser constantemente modificadas, transformadas, reajustadas... pois "todas as marcas, as formas, as eficácias e os funcionamentos dos corpos se transformam, mudam com o tempo, subvertem-se, substituem-se e representações deslocam-se" (OLIVEIRA, 2006, p. XIII). Essas adequações, contudo, são reguladas pela constituição de uma racionalidade objetiva representadas, principalmente, pelos parâmetros tecnológicos intercedidos, sobretudo, pela ciência.

As ginásticas constituíram uma grande sistematização científica e pedagógica nessa empreitada de adestramento do corpo, de inscrição de novos gestos, de "qualificação" do movimento e de governo da vontade, permitindo não só a visibilidade das performances corporais, mas também dos efeitos do exercício sobre o corpo em sua totalidade ou em suas partes (SOARES, 2008, p. 78).

Segundo Soares (2008, p. 77), os métodos de se exercitar, as ginásticas, foram sistematizadas cientificamente no princípio do século XIX na Europa pela figura de Amoros (1970-1848) quando escreve um Manual de Ginástica para os franceses, cuja primeira edição data de 1834. Com Amoros emerge a preocupação de tornar a ginástica uma ciência explicitada sobre os fundamentos da Física e da Biologia. Não mais que duas décadas acentuou-se da ginástica um caráter terapêutico, de enfrentamento da indolência e da preguiça. "Amoros foi aquele que, de certo modo, concretizou um projeto científico e estético redefinindo ali o lugar do corpo na sociedade" (SOARES, 2002, p. 62). Este se associou não apenas a sistematização dos exercícios, mas também ao uso de aparelhos mecânicos, à criação dos ginásios, locais propícios para o exercício da prática, bem como em relação ao uso adequado do tempo. Holt e Vigarello (2008, p. 467), afirmam que:

[...] os reinventores da ginástica garantem ter descoberto uma ciência: "a ciência racional de nossos movimentos". A maioria, notáveis ou médicos, responsáveis pelas sociedades de ginástica, definem um conjunto exclusivo, única prática fundamentada e legitimada: "Os movimentos de ginástica diferem dos movimentos habituais no sentido de que são praticados segundo certas regras deduzidas da fisiologia e da experiência." A insistência é posta sobre "uma mudança metódica e cientificamente instituída".

Sem dúvida, Amoros foi um grande colaborador ao incutir um marco científico em tal prática, no entanto, é preciso rememorar que parâmetros referentes ao campo da ciência e suas atribuições ao que se refere ao contexto do "corpo" já estavam sendo postos, mesmo 
que minimamente, há séculos anteriores desde a constituição do movimento "revivalista"10 encabeçado por pensadores humanistas que ao retomar o período clássico para constituir parâmetros para uma nova sociedade colocam o homem e suas capacidades físicas e espirituais no centro das especulações definindo uma atitude que se tornou conhecida como antropocentrismo.

É perceptível que ao escrever o "Arte Gímnástico" Jerônimo Mercurial manifesta entusiasmo pela ciência dos exercícios físicos, ciência no sentido de um conhecimento profundo das possibilidades médicas dos exercícios sistematizados voltados para a conservação da saúde. Mercurial, assim como muitos outros homens do período renascentista, foi certamente um homem de ciência, mas em sua época esse aspecto, talvez, ainda estivesse em fase embrionária se comparada com os atuais moldes com que a mesma se apresenta neste início de século XXI. Ao longo de seu texto, o autor aponta a ginástica e a medicina enquanto duas "formas de Arte", mesmo ambas já possuindo características de uma "ciência", com regras, leis, preceitos, finalidades objetivas, etc. Este "arte ejercitatorio", no grego "jimnástica", conhece as potencias de todos os exercícios, "ó mas bien arte jimnástico es la ciência de poder hacer todos los ejercicios" (MERCURIAL, 1973, p. 10).

Sob a dedução de que alguns parâmetros científicos para a ginástica disseminados por Amoros no século XIX foram também postos, séculos antes, por Mercurial no "Arte Gímnástico" - no sentido de apontar algumas prerrogativas e pré-sistematizações dos exercícios (ginástica) com uma finalidade educativa concernente a conservação da saúde, como também sobre a ideia de uma ginástica terapêutica e ao uso dos ginásios e do tempo apropriado para a prática dos exercícios físicos - incute-se tais questionamentos que fundamentam e nos propõe a realizar as seguintes problemáticas: É possível identificar uma concepção científica da ginástica ainda no século XVI à partir de J. Mercurial? Será que J. Mercurial é um precedente das ideias desenvolvidas por Amoros? Porque Mercurial não foi e não é mencionando na construção histórica desse saber? Neste sentido, quais as possibilidades de pensar tais prerrogativas à partir de sua obra "Arte Gímnástico"?

Tais questões são emblemáticas no sentido de que Mercurial não é mencionando na construção histórica do conhecimento referente a ginástica no tocante a sua constituição enquanto uma prática social educativa e de civilidade. Julgamos que a principal contribuição da obra de J. Mercurial se relaciona com a construção de um conhecimento sobre os modos de educar o corpo pautados nos meados do processo civilizatório e suas imbricações científicas Se, porventura, J. Mercurial antecipa tais preceitos apontados por Amoros, de forma evidente, ou pelo menos se aproxima, é de tamanha riqueza conjecturar tais contribuições a partir da rememoração de outros pensadores referentes aos estudos sobre o "corpo", estes pautados de maneira hegemônica, sobretudo, a partir de Leonardo da Vinci (1452-1519) ${ }^{11}$ e Andreas Vesalius (1514-1564) ${ }^{12}$ dos séculos XIV, XV e XVI e, especificamente, na Educação Física, a partir de Amoros (1970-1848), do século XIX.

Ao nos debruçarmos, enquanto pesquisadores, aos mares ínfimos e desconhecidos da História ficam aqui as prerrogativas que se tornam necessárias aprofundar e tornar viva a imagem de Mercurial que têm muito a contribuir. A riqueza da obra, sua apropriação e reunião de saberes de diversas ordens e de pensadores do período clássico, as inquietações históricas que se repercutiram através de sua obra, a ausência de fontes, etc. são algumas das pontuações que seduz o pesquisador e ao mesmo tempo relevam a importância de realizar um estudo pautado sobre tal obra. Assim, ficam as prerrogativas acerca da necessidade em se pautar mais estudos que precedem o "século das luzes" no tocante a percepção científica no campo da ginástica - pedagogia ou técnica responsável pela educação do corpo. 
Não podemos deixar o passado cair no esquecimento, deixar que prevaleça o silêncio no momento em que o "mar desconhecido" agita tempestuosamente as suas estruturas. A apropriação histórica pensada sob a materialidade de uma memória que se encerra na obra de J. Mercurial, pautada nas perspectivas acadêmicas do campo da história da Educação Física ou da Educação do Corpo, confere inúmeras possibilidades de reajustes ou ressignificações da história, seja para regular a compreensão do presente ou na projeção do futuro.

\section{Considerações finais}

Objetivamos nesse ensaio trazer à baila uma obra que entendemos fundamental ao avanço da área de Educação Física e que ainda suscita questões essenciais ao debate contemporâneo das relações saúde e educação. Ao taxarmos o "Arte Gimnástico" de Jerônimo Mercurial como uma obra monumental não nos referimos ao gigantismo da mesma, mas à necessidade de avançarmos à crítica histórica como nos propõe Le Goff (1990). Tomamos emprestado da distinção entre Monumento, aquilo que é produto do passado e, portanto, restringe-se à memória, e Documento aquele material trazido ao presente pelo historiador para nos ensinar sobre o passado, a necessidade de provocar e trazer a obra de Mercurial ao centro do debate histórico.

Reiteramos com Le Goff (1990, p. 549), que "o novo documento, alargado para além dos textos tradicionais, transformado - sempre que a história quantitativa é possível e pertinente - em dado, deve ser tratado como um documento/monumento". De onde a urgência de elaborar uma nova erudição capaz de transferir este documento/monumento do campo da memória para o da ciência histórica.

Façamos da obra de Mercurial a devida leitura enquanto um documento/monumento à área de Educação Física e aprendamos com ele com as devidas contextualizações e textualizações.

Por fim, e ratificando o Monumento da obra de Mercurial, necessário reiterar a última justificativa de leitura e análise do "Arte Gimnástico", a noção de Clássico. Para tanto, cabe resgatarmos os ensinamentos de Ítalo Calvino (1993).

O clássico nem sempre nos ensina sobre o que não sabíamos, podemos descobrir nele algo que sempre soubéramos ou acreditávamos saber, mas desconhecíamos que ele o dissera primeiro. Ou seja, é clássico aquele que sabemos colocar no devido lugar de sua genealogia. Para muito antes dos iluministas, um renascentista já dizia muitos dos discursos tão reiterados hoje como símbolos da "modernidade". De igual modo, cabe à Universidade e aos que estudam História da Educação e da Educação Física resgatar a obra de J. Mercurial para o devido situar no seu contexto histórico como Monumento e a devida crítica histórica a esse Documento/Monumento.

\section{Referências}

ADORNO, T. W; HORHEIMER, E. M. Dialética do Esclarecimento. Rio de Janeiro, Jorge Zahar, 1985.

BRANDL NETO, I.; CAMPOS, I.G. A influência da mídia sobre o ser humano na relação com o corpo e a auto-imagem de adolescentes. Caderno de Educação, v. 9, n. 17, Marechal Cândido Rondon, p. 87-99, $2^{\circ}$ sem., 2010. 
CALVINO, I. Por que ler os clássicos. 2. ed. São Paulo: Companhia das Letras, 1993.

CHARTIER, R. A história ou a leitura do tempo. Belo Horizonte: Autêntica, 2009.

Escutar os mortos com os olhos. Estudos Avançados. v. 24, n. 69, Rio de Janeiro, p. 7-30, 2010.

FOUCAULT, M. Vigiar e punir. Rio de Janeiro: Vozes, 2000.

GAGNEBIN, J. M. Lembrar escrever esquecer. São Paulo: Editora 34, 2006.

HALBWACHS, M. A memória coletiva. São Paulo: Vértice, Editora dos Tribunais, 1990.

HOLT, R.; VIGARELlO, G. O ginasta e a nação armada. In: COURBIN, A.; COURTINE, J.; VIGAREllO, J. (Org.). História do Corpo. v. 2. Petrópolis: Vozes, 2008.

JAEGER, W. Paideia: a formação do homem grego. São Paulo: Herder, 1995.

LE GOFF, J. História e Memória. Campinas: Unicamp, 1990.

MERCURIAL, J. Arte Gímnástico. Madrid: Delegacion Nacional de Educacion Física y Deporte, 1973.

OLIVEIRA, M.A.T. (Org.). Educação do corpo na escola brasileira. Campinas: Autores Associados, 2006.

POLLAK, M. Memória, esquecimento, silêncio. Estudos Históricos, v. 3, n. 2, Rio de Janeiro, p. 3-15, 1989.

SOARES, C.L. Imagens da Educação no corpo: estudos a partir da ginástica francesa no século XIX. 2. ed. Rev. Campinas: Autores Associados, 2002.

. Pedagogias do corpo: Higiene, ginásticas, esporte. In: MARGARETH, R.; VEIGA-NETO, A. (Org.). Figuras de Foucault. 2. ed. Belo Horizonte: Autêntica, 2008.

\footnotetext{
${ }^{1}$ Mestranda em Educação pela Universidade Federal de Sergipe - UFS. Graduada em Educação Física pela UFS. Membro do grupo de Pesquisa "Corpo e Governabilidade: política, cultura e sociedade" do Departamento de Educação Física da UFS. E-mail: vitorino.jessica@gmail.com

2 Professor do Departamento de Educação Física da UFS. Professor do Programa de Pós-graduação em Educação da UFS. Doutor em Educação Pela Universidade Federal da Bahia - UFBA. Membro do grupo de Pesquisa "Corpo e Governabilidade: política, cultura e sociedade" do Departamento de Educação Física da UFS. E-mail: zobolito@gmail.com

${ }^{3}$ Professor do Departamento de Educação Física da UFS. Professor do Programa de Pós-graduação em Educação da UFS. Doutor em Educação Pela Universidade Federal da Bahia - UFBA. Coordenador do grupo de Pesquisa "História, Sociedade e Educação no Estado de Sergipe" (NPSE/UFS). E-mail: hamilcarjr@hotmail.com
}

Revista HISTEDBR On-line, Campinas, $n^{\circ}$ 63, p. 330-341, jun2015 - ISSN: 1676-2584 
4 Ao final deste ensaio exploraremos a relação documento/monumento explicitada por Jacques Le Goff (1990) e a inserção da obra de Mercurial nesse contexto.

${ }^{5}$ Para Gagnebin (2006, p. 55) rememorar “[...] implica uma certa ascese da atividade historiadora que, em vez de repetir aquilo de que se lembra, abre-se aos brancos, aos buracos, ao esquecido e ao recalcado, para dizer, com hesitações, solavancos, incompletude, aquilo que ainda não teve direito nem à lembrança nem às palavras".

6 Jerônimo Mercurial (1530-1606) se notabilizou popularmente através do "Arte Gímnástico", a sua obra mais famosa e mais original. Nesta o autor aborda a ginástica em constantes relações entre o antigo e o moderno, e vice-versa, estas dos quais é o precursor.

${ }^{7}$ De acordo com o editor de Mercurial (1973), o Arte Gímnástico foi publicado em um número de oito edições sucessivas $(1569 ; 1573 ; 1577 ; 1587 ; 1601 ; 1644 ; 1672 ; 1737)$ fora as quatro versões identificadas publicadas e republicas em outras localidades (1845 - primeira versão espanhola/Madrid; 1737 - primeira versão veneziana/Veneza; 1856 - primeira versão italiana/Itália; 1973 - segunda versão espanhola/Madrid).

8 De acordo com Halbwachs (1990, p. 36) trata-se de memória coletiva "[...] quando evocamos um acontecimento que teve lugar na vida de nosso grupo e que considerávamos; e que consideramos ainda agora, no momento em que nos lembramos, do ponto de vista desse grupo".

${ }^{9}$ São eles: " 1 o. Todo lo que ha de tomar el enfermo se reduce á comidas ó bebidas usuales ó medicinales. $2^{\mathbf{o}}$. Todo lo que toca á la evacuación se comprende en el sudor, escremento, saliva, orina y cosas semejantes. $3^{\circ}$. Los medicamentos esternos en el agua, aire, salitre, mar, aceite y otros de este jenero. $4^{\circ}$. Los que se deben hacer en los ejercicios, estudios, vijilas, sueño, liviandad venérea, ira, cuidado y lavativas" (MERCURIAL, 1973, p. 7).

${ }^{10}$ Revivalismo foi um termo bastante utilizado em diversos momentos ao longo da história universal no sentido de denominar os fenômenos/movimentos que tentaram resgatar tradições, princípios, valores espirituais, sociais e/ou culturais do passado, principalmente quando este passado se reporta a momentos de grandeza e esplendor. Neste caso, estamos nos referindo ao "Movimento Renascentista" a qual se imbuiu deste caráter ao tentar recuperar/reviver as tradições ou referências culturais da antiguidade clássica.

${ }^{11}$ Artista, engenheiro e proto-cientista. Interesses outros também o direcionou à arte da dissecação.

${ }^{12}$ Médico belga, considerado o "pai da anatomia moderna".

Recebido: julho-15 Aprovado: agosto-15 